8-6-2018

\title{
Storm Clouds on the Horizon: Feminist Ontologies and the Problem of Gender
}

\author{
Pamela L. Caughie \\ Loyola University Chicago, pcaughi@luc.edu \\ Emily Datskou \\ Loyola University Chicago \\ Rebecca Parker \\ Loyola University Chicago
}

Follow this and additional works at: https://ecommons.luc.edu/english_facpubs

Part of the English Language and Literature Commons, and the Feminist, Gender, and Sexuality Studies Commons

\section{Recommended Citation}

Caughie, Pamela L.; Datskou, Emily; and Parker, Rebecca. Storm Clouds on the Horizon: Feminist Ontologies and the Problem of Gender. Feminist Modernist Studies, 1, 3: 230-242, 2018. Retrieved from Loyola eCommons, English: Faculty Publications and Other Works, http://dx.doi.org/10.1080/ 24692921.2018.1505819

This Article is brought to you for free and open access by the Faculty Publications and Other Works by Department at Loyola eCommons. It has been accepted for inclusion in English: Faculty Publications and Other Works by an authorized administrator of Loyola eCommons. For more information, please contact ecommons@luc.edu. (c) Informa UK Limited 2018 


\title{
Storm Clouds on the Horizon: Feminist Ontologies and the Problem of Gender \\ Pamela L. Caughie, Emily Datskou, and Rebecca Parker
}

\begin{abstract}
Feminist digital humanities is no longer focused primarily on recovering and preserving works by women authors. Feminist scholars are currently engaged in changing information design and data visualizations. However, as feminists seek to create new ontologies of gender, they face difficulties posed not only by current encoding standards, but by changing concepts of gender. Can ontologies ever capture the complex, multi-layered, dynamic nature of gender identities? This question is especially challenging when dealing with modernist works that represent gender and sexual identities at the very moment of their emergence as such. Our work on a digital edition and archive of Man into Woman (1933), the life narrative of Lili Elbe, one of the first persons to undergo gender affirmation surgery, has brought home to us both the pressing need for feminist interventions in data models and gender ontologies, and the difficulties if not impossibility of any adequate ontology of gender. In answer to the question posed above, we respond, only if we revise our concept of what the end result is: the linked data network visualization must capture a temporal process and not a snapshot of a static moment or even series of moments.
\end{abstract}

When we think about feminism and the digital humanities, we most often gravitate to stand-alone digital projects devoted to major women writers—such as Mina Loy: Navigating the Avant-Garde, The Marianne Moore Digital Archive, and Woolf Online - and to works by women made available through aggregated resources, such as Gertrude Stein's and Edith Sitwell's Hogarth Press publications in the Modernist Archives Publishing Project, The Note Books of a 
Woman Alone (1935) by Evelyn Wilson in Modernist Networks, and the TEI-encoded texts by lesser-known British women writers in The Victorian Women Writers Project. ${ }^{1}$ Feminist digital humanities understood in terms of subject matter makes digitization mainly about the feminist project of recovering, preserving, and making accessible the works of women authors.

Increasingly, though, feminist digital humanities scholars such as Susan Brown, Laura Mandell, and Miriam Posner have employed feminist theoretical concepts and practices in work on information design and data visualization, conceiving feminism as an intervention aimed at interrogating and changing not just who gets digitized but how such digitization necessitates new data models and interfaces. "Feminism is not (just) about women," write Catherine D'Ignazio and Lauren F. Klein, "but rather draws our attention to questions of epistemology—who is included in dominant ways of producing and communicating knowledge and whose perspectives are marginalized." ${ }^{\prime 2}$ A feminist practice, as D'Ignazio and Klein propose, calls on us to rethink binaries, to consider context, to situate knowledge in terms of a subject's position, and to legitimize embodiment and affect. Such interventions in structures and practices evolve from feminists' engagement with writing by women and sexual minorities. That is, the dual aspect of feminist digital humanities—subject and design—is recursive and mutually sustaining.

Our current collaboration on a modernist-era work has brought home to us the pressing need for feminist interventions in data models and gender ontologies. We are each contributing to a comparative scholarly edition (print and digital) of Man into Woman (1933), the life narrative of Lili Elbe, who, as Danish artist Einar Wegener, underwent one of the first surgical changes in sex in $1930 .{ }^{3}$ Initially co-editors Pamela Caughie and Sabine Meyer conceived the project primarily as an act of recovery, preservation, and dissemination of this important work in "sexological modernism" ${ }^{4}$ and the history of transgender. The editors wanted to make this multi- 
version work, as well as archival materials providing insight into its composition and reception, available to scholars and the general public through digitally scanned and TEI-encoded texts. Additionally, a collation tool will enable users to see where and how the typescript and four primary editions in three languages vary in terms of narrative elements, pronoun choices, and paratextual materials. ${ }^{5}$ But the deeper we got into mark-up, the more evident it became that the categories and hierarchies available to us were inadequate for our task. We not only had to deal with the occasional difference in gender attribution across the editions, but we also had to identify a male subject who at times presents himself as masquerading as a woman, at others as being inhabited by one, and who eventually becomes a woman, in a life history narrated retrospectively from the perspective of Lili Elbe. Imagining what a cloud visualization might look like for Lili Elbe's narrative, we joked that we needed a storm cloud to capture the unsettled and unsettling instances of gender in this work and the way the narrative envisions something new forming on the horizon of gender in the modernist era.

Our awareness of the inadequacies of current encoding practices crystalized for us at the “Transformative Digital Humanities" conference held at Loyola University Chicago in March 2018 in which the three of us participated. Subtitled "Feminist Interventions in Structure, Representation, and Practice," the conference featured scholars and students working to create more complex and nuanced ways to represent gender and race in digital humanities. ${ }^{6}$ Keynote speakers Susan Brown and Laura Mandell kicked off the event by discussing their separate but coextensive projects, both seeking to contribute to more inclusive ontologies that are "historically sensitive" and "dynamic" enough to enable discoveries of non-normative genders through "big data" visualization. Their ontological work, like digital humanities projects that focus on specific writers, seeks "to expand the literary and historical canon to include groups that 
have been understudied or misrepresented by the print record" (conference description) by giving us access to information likely to be missed by rigid, stable, and limited ontologies. ${ }^{7}$ Rather than simply identifying specific types of genders or sexualities, expanding gender types by adding new terms such as "genderqueer" and "transgender," as The Orlando Project has already done, ${ }^{8}$ Brown and Mandell propose that new ontologies of gender might be configured around “character clusters." For example, Mandell works with separate teams of encoders each marking different character qualities and functions in a work: undergraduates are coding for character traits and activities, the graduate students for character function in novels and essays (e.g., protagonist, narrator), and Mandell for gender normative or non-normative characteristics based upon the undergraduates' codes and set in relation to characters or authors.

By bringing together different datasets, such an approach to gender ontologies (which are necessary to make visible data now left out of computational analytics and its data visualizations) can be understood as relational and intersectional. Ontologies in this sense can, ideally, provide information about the social, cultural and historical milieu without pigeonholing characters. As Brown and Mandell put it, ontologies are representations, not essences, tropes not types, and as such do not escape cultural mediation; thus, they should be designed to bring such mediation to the fore. The challenge is finding ways to leave gender variance and gender non-conforming types ambiguous and dynamic but still findable. ${ }^{9}$ Such “ontological agility," Brown and Mandell admit, is at odds with current data structures and hierarchies, which raises the question, can gender identity, which is complex and multi-layered, ever be ontologized?

This question is especially challenging when digitizing modernist works typified by Virginia Woolf's Orlando, Djuna Barnes Nightwood, or Radclyffe Hall's Well of Loneliness that represent gender and sexual identities at the very moment of their emergence as such. The 
concept of identity is popularly understood to be a post-World War II phenomenon identified with the work of Erik Erikson and the term "identity crisis." However, during the 1920s, identity was already being conceptualized: for anthropologists, identity signified differences between cultural groups; Sigmund Freud focused on individual psychosexual development; and sexologists associated identity with a felt sense of gender embodiment. Terminologies for gender and sexual identity in particular bourgeoned in the later nineteenth and early twentieth centuries as sexologists attempted to parse distinctions among types of "sexual perversion": Urning and sexual invert, pederast and homosexual, Eonist and transvestite, sexual intermediate and third sex, androgyne and gyander, to name some of the more prominent neologisms. ${ }^{10}$ Not only were there many terms for the same phenomena but any one term could encompass various phenomena. Sexologists as well as their patients and correspondents were using terms from different conceptual frameworks interchangeably, which led to inconsistencies in the employment of terminology. By 1918 when he published his autobiography, Earl Lind (a.k.a. Ralph Werther and Jennie June) could identify as an androgyne, an invert, a homosexual, a fairie, a girl-boy, and a woman "whom Nature disguised as a man."11

Can computational models capture such taxonomic chaos? Originally, TEI standards offered only two choices for encoding gender: male and female. So when Hannah Gillow Kloster, an MA student in digital humanities at Loyola University Chicago, undertook to produce a digital edition of Virginia Woolf's Orlando: A Biography (1928) for her MA thesis in the early 2010s, Digital Orlando: A Novel by Virginia Woolf, she faced a conundrum. ${ }^{12}$ Although the TEI guidelines had recently been expanded beyond the initial binary of male or female, there was still no easy way to mark one person as two genders within the same text without removing the purpose of marking up gender in the first place. As Hannah explains, the tag for gender as 
outlined in the P5 TEI standards was permissible only in the listPerson element in the TEI header. ${ }^{13}$ This hierarchical hinderance means that there was no standard way to mark up a midtext gender shift, which occurs in Chapter Three of Woolf's fantastic novel when Orlando awakes to find he is now a she. Hannah circumvented this issue by creating two keys for Orlando's character, OrM and OrW, to be included in the persList element in the header. Although this allowed her to change the gender attached to Orlando's character midway through Chapter Three, it unfortunately suggests that Orlando turns into a different person, which is not the case in the novel. ${ }^{14}$ The two keys also suggest that gender is both a salient feature of Orlando's identity and an important element in the narrative. Yet while Orlando's sex change sparks discussions of gender socialization undertaken by Orlando's biographer, who narrates the novel, and by Woolf's readers, for Orlando, the sex change is not a defining moment. He simply wakes up a she. Nor does the change trouble other characters, including Orlando's servants, dogs, and suitor, the Archduchess Harriet/Archduke Harry. Jay Prosser has argued that the novel, despite the sex change, is not about transsexuality, indeed not about the sexed body at all; it's about the "cultural vicissitudes of gender." ${ }^{15}$ How can an ontology represent that?

This technical difficulty is only exacerbated by a conceptual one. One challenge for feminist interventions in gender ontologies is that the conceptualization of identity itself is not consistent across texts, theories, and times. The Oxford English Dictionary defines identity ontologically as "the quality or condition of being the same in substance, composition, nature, properties, or in particular qualities under consideration; absolute or essential sameness; oneness. ${ }^{.16}$ Yet identity entails far more than a list of characteristic features consistent across time and space. How one sees oneself, who one associates with, where one lives and travels, what one does or reads - a complex set of tags would need to be created to begin to map the 
corpus of identity for any one character. Concepts of gender and sexual identity in particular change over time with the currency of new terms, as noted above, such that Radclyffe Hall's Stephen Gordon can be called a sexual invert in the 1920s, a lesbian in the mid-twentieth century, and a transman in the 1990s. But gender attributes change across times and cultures as well, the very insight provided by Orlando's centuries-long lifespan. In a mid-twentieth-century life narrative, for example, Jan Morris (then James) reflects on her experience as a reporter accompanying the first British team to ascend Mount Everest in 1953 and remarks that it was a "specifically male accomplishment"; the categories that defined the men on this expedition could not easily be applied to women "of equal intelligence in similar circumstances." ${ }^{17}$ Yet Morris also concedes that by 1974, when she published her memoir, such traits could no longer be applied to men either:

Class has lost its binding function; patriotism has lost its elevating force; young men are no longer ashamed of weaknesses; the stiff upper lip is no longer an ideal, only a music hall sally. The barrier between the genders is flimsier now, and no expedition will ever again go to the Himalayas so thoroughly masculine as Hunt's. ${ }^{18}$

This insight is not specific to the 1950s. Sherwood Anderson, Djuna Barnes, T. S. Eliot, Aldous Huxley, D. H. Lawrence, Mina Loy, Virginia Woolf—all confront and strive to represent, in subject and form, changing notions of gender and sexuality in the early twentieth century. Indeed, as Caughie has argued elsewhere, the fluidity of identity boundaries that we have come to identify with postmodernity—especially a postmodern notion of identity as socially constructed, discursive, and fluid — has as much or more to do with the historical conditions of modernism as with the textual theories of post-structuralism. ${ }^{19}$

Notably, within modernist texts and post-structuralist theories alike, gender is conceived in relation to temporality, as a performative practice; identity shifts from something one is to something one does, as Judith Butler famously puts it. Gender, Butler writes, is not "a stable 
identity or locus of agency," one that can be captured in a snapshot, but is instead "an identity tenuously constituted in time, instituted in an exterior space through a stylized repetition of acts." ${ }^{20}$ This "formulation," according to Butler, "moves the conception of gender off the ground of a substantial model of identity to one that requires a conception of gender as a constituted social temporality. ${ }^{21}$ While Butler's discussion of gender as performative has become a foundation of gender and queer theory, the importance of temporality within her discussion is often overlooked. This element of temporality is especially relevant to transgender, and especially critical to our thinking about digital ontologies of gender identity. Transgender intensifies the temporality of identity insofar as the very term "trans" connotes movement. As Caughie comments in her article on Orlando and Man into Woman, the difficulty of pinpointing when the term transsexual achieved sufficient coherence and stability to be marked as a distinct identity may be equated with the difficulty of specifying precisely when the transsexual's transition from one sex to the other begins and ends. ${ }^{22}$ Thus, any model of gender as performative must take into account not just the social aspects of identity (identities are produced for and by others) but the temporal aspects as well (behaviors need to be reiterated over time to produce a gender identity). Thus, we need what we call a "trans ontology," a model that captures the process of gender identity formation not a snapshot of the character formed. Derived from our work on trans narratives, this model would not only foreground the movement implicit in identity but also illustrate the recursive and mutually sustaining relationship between subject and representation that we view as fundamental in feminist digital humanities.

With respect to specific modernist narratives and gender and sexual ontologies, what does one do, for example, with Stephen Gordon in Hall's The Well of Loneliness (1928)? Although the narrative identifies Stephen with sexual inversion, understood as a congenital 
disorder, Stephen herself never accepts that label. She goes from asking "What am I?" to stating "being what I am" without naming what she is. ${ }^{23}$ In fact, Stephen consistently rejects identification with those termed "inverts." At the time of Hall's writing, "sexual inversion" conflated homosexuality with what Hirschfeld named transvestism and what we call today transgender. Thus, to her father, who reads Karl Ulrichs and Richard von Krafft-Ebing, Stephen is an invert; to her mother Stephen is an abomination, a sin against nature; to Mary she is a female husband; to many she is simply queer. Any gender ontology would have to be flexible enough to capture these various designations in the context of specific relationships, and indefinite enough to resist pinning Stephen down to any one identity.

Similarly, Djuna Barnes's character Dr. Matthew O’Connor in Nightwood (1936) defies gender ontologies. In an early scene excised by T. S. Eliot in the published version, the doctor relates to Frau Mann his experience of being caught in an alley having sex with a man. While being fondled by the hands of a stranger, he felt the "less pleasing hand, the hand of the law" touch him on the shoulder. ${ }^{24}$ The doctor's description of the obscenity trial makes clear that he had been charged with a homosexual act. However, in a later chapter "Watchman, What of the Night?", he is presented as a cross-dresser. Nora Flood makes an unannounced visit to the doctor's room, finding him in bed "in a woman's flannel nightgown" and wearing "a wig with long pendent curls that touched his shoulders." 25 Later in the chapter transvestism morphs into sexual inversion understood as cross-gender identification: "Misericordia," the doctor intones, “am I not the girl to know of what I speak?":

In the old days I was possibly a girl in Marseilles thumping the dock with a sailor .... [a]m I to blame if I've turned up this time as I shouldn't have been, when it was a high soprano I wanted .... [F]or, no matter what I may be doing, in my heart is the wish for children and knitting. God, I never asked better than to boil some good man's potatoes and toss up a child for him every nine months by the calendar. ${ }^{26}$ 
In order to capture Matthew O'Connor's gender identity digitally, we would need more than to add "sexual invert" to our mark-up. Relevant here is the recent conversation in the TEI community regarding the representation of gender simplified to single-letter attributes ( $\mathrm{M}$ for male, $\mathrm{F}$ for female, $\mathrm{O}$ for other, $\mathrm{N}$ for non-applicable, $\mathrm{U}$ for unknown). ${ }^{27}$ Simply adding I for invert or T for transgender would not suffice. Barnes's novel, though heavily influenced by sexological discourse of the 1920 s, uses the term "invert" only once, and that is in relation to Robin Vote, not Matthew O'Connor. And “transgender" is a contemporary concept of limited use in conveying a modernist understanding of gender. A visualization of "character clusters" would not suffice either, for Matthew identifies as a woman and a doctor, a son and a Catholic but not sufficiently or consistently enough to have any one primary identity prevail. Moreover, the nuances of sexuality and dress would be lost. As Miriam Posner notes, "the most common types of data visualization ... are great for quickly conveying known quantities but terrible at conveying uncertainty or conflicting opinions, ${ }^{, 28}$ such as we see in Barnes's novel and in much modernist writing. Thus, we need a trans ontology that is situational and relational, capable of apprehending shifting identities in space and time.

Even if digital ontologies were able to show changes in identity over time via, for instance, a timeline, they would still not be able to illustrate accurately how temporality works within any one identity. The necessary separation of gender into individual data points might erroneously suggest a progressive and forward trajectory towards a fixed point, as in the notion of transsexualism as a transition from one gender to another. Additionally, how do we take into account the identities or characteristics given to characters by others? For example, in a wordfrequency cloud, typically the most used words in a text show up. But it would take an extensive, complex mark-up that has not yet been standardized to know if those words are being applied to 
the character (e.g., how society labels certain behaviors or traits) or are used by the character (e.g., how the subject identifies). Some transwomen, for example, want to be identified simply as women, others want to acknowledge their transness. Lili Elbe identified herself as "a real girl."29 Are ontologies naming how others, including the encoders, label characters or how characters identify themselves? These questions emphasize the importance, as Brown and Mandell noted in their lecture, of distinguishing whether the visualization is of the data or of the text itself. We have to build our ontologies from the end-goal of what we want the visualization to disclose.

With respect to gender ontologies considered from the perspective of transgender, the question then becomes, can we present gender as a social-temporal process? Current visualization models, for example, do not take into account the relational aspect of identity; they tell us the occurrence rate for specific data, whether characteristics, behaviors, or words, but they do not necessarily tell us when in the text this data occurred. For example, the conception of Orlando's beautiful legs_ - a key trait—changes with the passage through different eras. In the first chapter set in the age of Queen Elizabeth I, that feature signifies masculinity, yet by the fourth chapter set in the age of Queen Victoria, the same feature signifies femininity. Can data analytics capture such a temporal shift? Or, if a visualization showed that "invert" were a dominant word in a modernist work, as it is in The Well, does this signify that inversion is a dominant characteristic of a character's identity? What if most uses of "invert" occur in the beginning of a text? Might that suggest "invert" was heavily discussed and then rejected as an identity category, or that "invert" was used within a specific period in the text among specific people and not with other people later in the text? What if a character displays a particular attribute with only one other character, might that not say more about their relationship than about the character's identity? All of these explanations are possible and all affect how we 
conceptualize identity and gender ontologies, but not all can be captured in the static, snapshot visualizations commonly used. Indeed, such data analytics could be misleading. Given that the word "invert" appears over a hundred times in The Well but only once in Nightwood, a visualization might erroneously suggest that The Well is the queerer text.

With respect to our digital project, Man into Woman poses many of the same problems presented by Woolf's, Barnes's, and Hall's novels. The first decision we had to make in encoding this text was whether or not to tag "Andreas Sparre" (the fictional name given to Einar Wegener in the narrative) and "Lili Elbe" as the same person, in keeping with current practices in transgender scholarship. Our decision to forego this practice was based on the thrust of the narrative logic, as indicated by the title (in the original Danish, Fra Mand til Kvinde, From Man to Woman), which insists on a distinction between the two. "Andreas Sparre was dead," the narrative states emphatically after Lili's third operation. ${ }^{30}$

Yet within the text that distinction is upheld inconsistently, and comes about slowly as Lili begins to deal with her newly embodied identity. Chapter VIII opens with a continuation of his life narrative that Andreas, who has been cross-dressing as Lili for years, recites to his friends Niels and Inger on the eve of the first operation in Berlin: "So Lili and I continued to live our double life, and no one, neither the 'initiated' nor myself, saw in this anything else than a pleasant kind of distraction and entertainment, a kind of artists' caprice. ${ }^{31}$ Lili is presented here as a performance. Yet already Lili has acquired her own set of friends, her own memories, and her own habits "which had nothing whatever to do with me," Andreas says. ${ }^{32}$ Are "Lili and I" "one and the same" in this double life, or two separate people in one body, as both Andreas and Lili insist elsewhere? At the end of the previous chapter, and before any surgical intervention, Andreas and his wife Grete play a joke on his parents by presenting Lili to them as a Parisienne. 
The parents know only Andreas, they have no knowledge of Lili, and they are incredulous to learn that "Andreas and Mademoiselle Lili from Paris are one and the same person." 33 Tellingly, it is not Andreas who reveals the truth to his parents, but Lili: "when she suddenly disclosed her identity, they ... could no longer trust their own eyes."34 That identity, presumably, is their son, Andreas.

Keeping the characters separate not only supports the narrative logic, as noted above, but also enables us to indicate when the two characters are present in the same scene. For example, after the first operation, a castration performed in Berlin, the narrative begins to refer to the subject as Lili. Before entering the Women's Clinic in Dresden, where the two remaining procedures will be performed, Lili must return to Dr. Karner, who drew Andreas's blood before the first operation. The doctor does not recognize her as Andreas. Surprised, and somewhat ashamed, she introduces herself as "Lili Sparre." "Sparre ... Sparre ...," the doctor ponders, much confused, "of course the name sounds familiar. Mr. Sparre was here about a fortnight ago. ... But I cannot call you to mind, madam." 35 To which Lili replies, "The gentleman and I, Doctor, are, in fact, one and the same person." 36 The doctor is all the more "dumbfounded," but then attributes the misattribution to Lili's lack of command of the German language. "The German language is a very difficult language," he tells Lili. "What you said before sounded very amusing - as if you had said that you and your husband were one and the same person." ${ }^{37}$ Here in a rare act of identification with Andreas, Lili's acceptance that they are "one and the same person" produces a comic effect, as in an earlier scene when Lili (Andreas cross-dressed for a carnival) has to fend off the advances of one of Andreas's classmates, ${ }^{38}$ or in the scene where a Count asks Andreas for the hand of his sister, Lili. ${ }^{39}$ 
Moreover, for our project, using the P5 TEI guidelines, gender ontologies are complicated by differences across languages. In the modernist era, "gender" was beginning to be used synonymously with "sex" in English-language writings whereas in German and in Danish, the other languages of this narrative, "gender" was solely a linguistic concept, not an identitarian one. This use of gender is consistent with past iterations of TEI guidelines still in use that categorize gender in terms of sex attribute values (e.g., M and F) and provide a "gen" element used specifically in relation to a linguistic representation of gendered words.$^{40}$ As an example of this grammatical complication, consider this passage from the American edition: "The next morning news came from Professor Kreutz in Dresden. Everything was ready for the patient's reception. If the patient's physical state allowed, the journey to Dresden might be undertaken immediately." ${ }^{41}$ In the English translation, the only pronoun used is "him," referring to Dr. Karner. In the Danish version, however, "hende" or "her" is used in reference to the patient: "Alt var parat til, at Patienten kunde komme, saafremt hendes Tilstand tillod hende at gøre Rejsen til Dresden" ("Everything was ready for the patient to come should her condition allow her to undertake the journey to Dresden”). ${ }^{42}$ The German reads “Alles sei zur Aufnahme bereit. Falls der körperliche Zustand des Patienten es im übrigen erlaube, könne sogleich die Reise nach Dresden angetreten werden" ("Everything would be ready for reception. If the patient's physical state allowed, the journey to Dresden could be undertaken immediately"). ${ }^{43}$ Again, no pronoun is used for the patient; "der Patient," gendered male in German, could be male or neutral. The passive voice construction in English elides any choice of pronoun, raising the question of just when the subject in this narrative is recognized as the "other sex."

Just as the editor and translators had to decide which pronoun to use for the patient, in encoding the English-language editions, we too have to decide how we capture that ambiguity in 
a multi-lingual text. Do we assign "der Patient" a sex value attribute, gendering the patient male (in contradiction of the Danish edition), or do we not, leaving it ambiguous? In the latter case, we lose data we cannot definitively encode; in the former, we lose a temporally-specific ambiguity.

To begin to handle this level of complexity, we need a trans ontology that can render the oscillation between gender identities, and the way gender is determined by the person or persons being addressed at a particular time in a particular location in a particular language. Posner points out the challenges: "technically speaking, we frankly have not figured out how to deal with categories like gender that are not binary or one-dimensional or stable. ${ }^{44} \mathrm{~A}$ useful model would have to deal with gender as time and place dependent, yet dealing with time in any way other than fixed dates is, technically speaking, a problem. An ontology formed around "clusters" of traits, as described above, is one model for approaching gender conceived as "shifting, performative, historically situated, etc. rather than fixed." ${ }^{45}$ Given that ontologies, as Brown and Mandell remind us, are representations that exist in a particular domain of discourse, another model suggested by our project might consist of clusters of discourses: e.g., terms from sexological discourse, those used in popular writings of the modernist era, terms from different cultures of the time, and terms currently in use in transgender studies. Then we might add some kind of overlapping and color-coding of these tags to reveal not what trans is but where the convergences and gaps are among these various terms, and how gender shifts over time and across discourse communities. Such an ontology, which has broader implications for how to visualize humanities data, would not just name reifications of identity categories but, as Brown and Mandell observe, might also reveal "possibilities forcibly foreclosed." 46

But even if we could establish temporal, spatial, and relational models of marking gender, would we be describing one particular narrative rather than creating linked open data capable of 
revealing patterns across narratives? If gender ontologies cannot accurately depict the temporal and situational aspects of gender are they, we wonder, always subject to producing essentialist representations of gender? In their presentation, Brown and Mandell acknowledge that "both within philosophy and computing/information studies, there is a lot of slippage towards positivism or essentialism in the ways that ontologies are approached and understood." ${ }^{\prime 47}$ And while their conception of gender derives from Butler's performativity, their methodology for producing a gender ontology may risk inadvertently reinforcing a substantive notion of gender as essentialist, and essential.

Any proposed solution to the project of gender ontologies forces us to confront a conundrum. On the one hand, gender ontologies, for all their hierarchical, Anglocentric, and metaphysical baggage, are crucial if we are going to map the formation and de-formation of gender across texts, times, and cultures. Ontologies could be helpful in showing where similar terms are being used in different ways, within a text and across texts, or how one person's gender/sexuality is being defined in different ways within a text. On the other hand, there may not be a technological solution to the difficulties posed by gender ontologies. Data will always be contextual, limited, and only proximate to any individual identity. Returning to our earlier question, can identities ever be ontologized?, our answer is, only if we revise our concept of what the end result is: the linked data network visualization must capture a temporal process and not a snapshot of a static moment or even series of moment. Our project has made us reconsider the process of creating an ontology that leads up to such visualizations, and part of understanding that process is taking into account the theorization of gender informing it as well as the temporality that is "forcibly foreclosed" in current models of gender and ontologies. 
Working on modernist texts such as Lili Elbe's has made clear to us the necessary messiness of any gender ontology. Confusion in gender and sexual terminologies in a text like Elbe's, though, is not something we should seek to clear up in terms of our present understanding of transgender. For that confusion is part of the experience of gender and sexuality in the modernist era, something to be realized and negotiated in readings of the narrative. Such negotiation can happen only in a collaboration among scholars, encoders, and users to navigate, not resolve, the temporal dynamics of identity and identification.

\section{Bibliography}

Barnes, Djuna. Nightwood. Second ed. New York: New Directions Books, 2006.

Brown, Susan and Laura Mandell. “Ontological Intervention.” Keynote lecture, Transformative Digital Humanities Conference, Loyola University Chicago, March 23, 2018.

Butler, Judith. Gender Trouble. New York: Routledge, 1990.

Caughie, Pamela L. “Passing as Modernism.” Modernism/modernity 12, no.3 (2005): 385-406.

Caughie, Pamela L. "The Temporality of Modernist Life Writing in the Era of Transsexualism." MFS: Modern Fiction Studies 59, no. 3 (Fall 2013): 501-25.

D’Ignazio, Catherine and Lauren F. Klein. "Feminist Data Visualization.” http://www.kanarinka.com/wpcontent/uploads/2015/07/IEEE_Feminist_Data_Visualization.pdf

Ehrenreich, Barbara. The Hearts of Men: American Dreams and the Flight from Commitment. New York: Anchor Press, 1983.

Elbe, Lili. Letter to Poul Knudsen. 1931. The Poul Knudsen Archive, The Royal Library, Copenhagen.

Gallon, Kim. "Making a Case for the Black Digital Humanities." In Debates in Digital Humanities, edited by Matthew K. Gold and Lauren F. Klein, 42-29. Minneapolis: 
University of Minnesota Press, 2016.

Gilmore, Leigh. "Obscenity, Modernity, Identity: Legalizing The Well of Loneliness and Nightwood." Journal of the History of Sexuality 4, no. 4 (1994): 603-624.

Hall, Radclyffe. The Well of Loneliness. New York: Anchor Books, 1990.

Hirschfeld, Magnus. Transvestites: The Erotic Drive to Cross Dress. Translated by Michael A. Lombardi-Nash. Buffalo: Prometheus Books, 1991.

Hoyer, Niels, ed. Man into Woman: An Authentic Record of a Sex Change. New York:

E. P. Dutton, 1933.

Lind, Earl. Autobiography of an Androgyne. Edited and introduction by Alfred W. Herzog. The Medico-Legal Journal, 1918; rept. Arno Press, 1975. Print.

Morris, Jan. Conundrum. 1974. New York: The New York Review of Books, 2002.

Peppis, Paul. Sciences of Modernism: Ethnography, Sexology, and Psychology. New York: Cambridge University Press, 2014.

Plumb, Cheryl J., ed. Djuna Barnes, Nightwood: The Original Version and Related Drafts. Normal: Dalkey Archive Press, 1995.

Posner, Miriam. "What's Next: The Radical, Unrealized Potential of Digital Humanities." In Debates in Digital Humanities, edited by Matthew K. Gold and Lauren F. Klein, 3241. Minneapolis: University of Minnesota Press, 2016.

Prosser, Jay. Second Skins: The Body Narratives of Transsexuality. New York: Columbia University Press, 1998.

Woolf, Virginia. Orlando: A Biography. New York: Harcourt, 1956.

Notes 
${ }^{1}$ Find the Mina Loy project at http://mina-loy.com/; the Marianne Moore Digital Archive at http://moorearchive.org/; Woolf Online at http://www.woolfonline.com/; the Modernist Archives Publishing Project at http://www.modernistarchives.com/; Wilson's The Note Books of a Woman Alone at http://drc.usask.ca/projects/notebooks/homepage.php; and The Victorian Women Writers Project at http://webapp1.dlib.indiana.edu/vwwp/welcome.do.

${ }^{2}$ D’Ignazio and Klein, "Feminist Data Visualization,” abstract.

${ }^{3}$ Modernists would have understood this procedure as a "sex change," a concept that emerges in the modernist era, though "sex change" need not involve surgery. Such a concept, Emma Heaney argues, implicitly assumes transwomen are not already women.

${ }^{4}$ Peppis, Sciences of Modernism, 102.

${ }^{5}$ Lili Elbe's life narrative was first published in Danish, shortly after Elbe's death in September 1931. The Danish version was translated from the German typescript compiled by Ernst Harthern, who published the work under the pseudonym Niels Hoyer. The typescript was then re-edited and published in German in 1932, so that the German edition is not a translation of the Danish and differs in significant ways. The German edition was then translated into English and published in Britain and the US in 1933. All references here are from the American edition.

${ }^{6}$ To define some of the terms we'll be using in this essay: Metadata is data that provides information about other data, such as title, author, and the relationship among versions. XML (eXtensible Markup Language) is a semantic markup language that describes textual features, such as paragraph breaks, emphasis, and dialogue. Standards for markup language, such as TEI (Text Encoding Initiative), and metadata standards, such as Dublin Core, provide a taxonomic and hierarchical data structure, nesting information in a prescribed order. An ontology, as defined by Brown and Mandell, provides a "representational vocabulary" for a particular domain of discourse and a model for describing relationships among types and properties that can be interpreted by and displayed for computer analysis.

${ }^{7}$ The third keynote speaker, Kim Gallon of Purdue University, presented on the dehumanizing of black lives that begins with data, specifically the way black people are interpolated by data, and how that data might be reconfigured. See Gallon, "Making a Case."

${ }^{8}$ Find the Orlando Project at http://www.artsrn.ualberta.ca/orlando/.

${ }^{9}$ Brown and Mandell, "Ontological Interventions."

${ }^{10}$ Some other terms include pseudo-hermaphrodite, physiological hermaphrodite, psychosexual hermaphrodite, and bisexual.

${ }^{11}$ Lind, Autobiography, 14. 
${ }^{12}$ Find the Digital Orlando project at

http://students.ctsdh.luc.edu/projects/finals/hannah/?node=content/text\&id=1.

${ }^{13}$ TEI, which stands for Text Encoding Initiative, is both a community and a set of standards for text encoding in XML (eXtensible markup language). The TEI guidelines (http://www.teic.org/Guidelines/P5/), as agreed upon by the TEI community, define the hierarchical relationship of elements and attributes used to represent a text/document in digital form.

${ }^{14}$ One obvious way to circumvent the gender assignment issues of TEI, Hannah explains, is to write a separate schema for Orlando. However, her project was in part "an exploration into using TEI for modernist fiction markup, and whether what it enables us to do outweighs its limitations, and if its status as the default Humanities/Textual Studies XML language is justified."

${ }^{15}$ Prosser, Second Skins, 168.

${ }^{16}$ Oxford English Dictionary Online, "Identity," 1a.

${ }^{17}$ Morris, Conundrum, 85-86.

${ }^{18}$ Ibid., 86.

${ }^{19}$ Caughie, "Passing as Modernism," 387.

${ }^{20}$ Butler, Gender Trouble, 191 (original emphasis).

${ }^{21}$ Ibid., 191 (original emphasis).

${ }^{22}$ Caughie, "Temporality," 505. Transsexualism was initially proposed by Magnus Hirschfeld in 1923, though he quickly abandoned the term in favor of an expansive understanding of transvestism.

${ }^{23}$ Hall, The Well, 152, 236.

${ }^{24}$ Plumb, Nightwood, 26. For a fascinating discussion of this passage, see Gilmore, "Obscenity, Modernity, Identity," 620.

${ }^{25}$ Barnes, Nightwood, 85.

${ }^{26}$ Ibid., 97-98.

${ }^{27}$ In January of 2013, Melissa Terras made the first formal request to the TEI community to halt the use of ISO/IEC 5218 standards (https://en.wikipedia.org/wiki/ISO/IEC 5218) in the TEI guidelines as the recommended standard for sex attribute values (https://github.com/TEIC/TEI/issues/426). By April 2013 the TEI guidelines and schema reflected the community conversation, broadening the accepted sex attribute values. Today, 
remnants of this conversation can be seen in the following P5 Guidelines "sex" element "value" attribute note (http://www.tei-c.org/release/doc/tei-p5-doc/en/html/ref-sex.html).

${ }^{28}$ Posner, "What's Next," 33.

${ }^{29}$ Lili Elbe, letter to Poul Knudsen, 31-01-31, The Poul Knudsen Archive, The Royal Library, Copenhagen.

${ }^{30}$ Hoyer, Man into Woman, 242.

31 Ibid., 92.

${ }^{32}$ Ibid., 95.

${ }^{33}$ Ibid., 91.

${ }^{34}$ Ibid., 91 (emphasis added).

${ }^{35}$ Ibid., 146.

${ }^{36}$ Ibid., 146.

${ }^{37}$ Ibid., 148.

${ }^{38}$ Ibid., 67-68.

${ }^{39}$ Ibid., 89.

${ }^{40}$ To read more about these TEI guidelines, see "Names, Dates, People, Places," section 13.3.2.1, at http://www.tei-c.org/release/doc/tei-p5-doc/en/html/ND.html.

${ }^{41}$ Hoyer, Man into Woman, 145.

${ }^{42}$ Fra Mand, 94.

${ }^{43}$ Ein Mensch, 123-124.

${ }^{44}$ Posner, "What's Next," 34.

${ }^{45}$ Brown and Mandell, “Ontological Interventions.”

${ }^{46}$ Ibid.

${ }^{47}$ Ibid. 